\title{
Reversibility of the Martensitic Transformations and Shape-Memory Effects
}

\author{
V. A. Lobodyuk \\ G. V. Kurdyumov Institute for Metal Physics, N.A.S. of Ukraine, \\ 36 Academician Vernadsky Blvd., \\ UA-03680 Kyiv-142, Ukraine
}

The results of the investigations of main peculiarities and reversibility of the martensitic transformations in different materials are considered and discussed. Unusual mechanical properties such as shape-memory effect, superelasticity, superplasticity, and other phenomena caused by these transitions are also analysed. The values of the recovering deformation are determined by the mechanism of the martensitic transformations and their reversibility. Reasons for their differences for the alloys with different characters of the martensitic transitions are also discussed.

Розглядаються й обговорюються результати досліджень основних особливостей та оборотности мартенситних перетворень в різних матеріялах. Проводиться аналіза таких незвичайних механічних властивостей, як ефект пам'яти форми, надпружність, надпластичність, та інших явищ, спричинених такими переходами. Величини відновлюваної деформації визначаються механізмом мартенситних перетворень та їх оборотністю. Також обговорюються причини їхніх різних значень у стопів із різними характерами мартенситних переходів.

Рассматриваются и обсуждаются результаты исследований основных особенностей и обратимости мартенситных превращений в различных материалах. Проводится анализ таких необычных механических свойств, как эффект памяти формы, сверхупругость, сверхпластичность, и других явлений, вызванных такими переходами. Величины восстанавливаемой деформации определяются механизмом мартенситных превращений и их обратимостью. Также обсуждаются причины их разных значений у сплавов с различными характерами мартенситных переходов.

Keywords: alloy, phase, martensitic transformation, reversibility, morphology, defect structure. 
Ключові слова: стоп, фаза, мартенситне перетворення, оборотність, морфологія, дефектна структура.

Ключевые слова: сплав, фаза, мартенситное превращение, обратимость, морфология, дефектная структура.

(Received October 1, 2015)

\section{CONTENTS}

1. Introduction

2. Main characteristics and peculiarities of the martensitic transformations

2.1. Types of the martensitic transformations

2.2. Morphology and fine structure of the martensitic crystals

2.3. Interphase boundaries 'martensite-parent phase': structure, state, mobility

3. Reversibility of the martensitic transformations (MT)

3.1. Mechanisms of the reconstruction during MT

3.2. Defect structure changes during direct-reverse MT

3.3. Relaxation of the stresses arising during MT

4. Unusual mechanical properties and phenomena caused by the martensitic transformations

4.1. Shape-memory effect

4.2. Two-way (reversible) shape-memory effect

4.3. Superelasticity

4.4. Superplasticity

4.5. Memory effects in small-size objects

4.6. Influence of the external impacts on shape-memory effect and recovery degree

5. Conclusions

References

\section{INTRODUCTION}

Discovery, investigation and widespread utilization of so unusual properties and phenomena caused by the martensitic transformations (MT) as shape memory effect (SME), superelasticity (SE), superplasticity (SP) led to a further increase of interest to this type of phase transformations in solids. All these properties are largely due to the reversibility - the important characteristic of the martensitic transformation, which was established by G. V. Kurdyumov in 1936 [1]. Just reversibility in a wide sense, i.e. reversibility of the crystal and defect structures during direct-reverse MT and restore of the original state after the reverse transition, causes these 
unusual properties and defines different degree of their proceeding.

In this review, the main peculiarities and mechanisms of the reconstruction during martensitic transformation in various alloys, its reversibility, caused by this transition unusual mechanical properties and phenomena, the reasons for their differences in the alloys with different character of the martensitic transition are described and discussed.

\section{MAIN CHARACTERISTICS AND PECULIARITIES OF THE MARTENSITIC TRANSFORMATIONS}

This section describes the main characteristics and peculiarities of the martensitic transformations: types of MT, temperature intervals and hysteresis of the transformation, morphology and fine structure of the martensitic crystals, phase boundaries of the 'martensite-initial phase', their state and mobility. These parameters and properties determine largely the structural reversibility of the MT.

\subsection{Types of the Martensitic Transformations}

The following definition of the martensitic transformation proposed by G. V. Kurdyumov in 1936 [1] already became classic: 'Martensitic transformation takes place by a regular lattice reconstruction in which neighbouring atoms are not interchanged by their places but only shifted relative to each other by a distance not exceeding the interatomic'. This formulation reflects all the basic common peculiarities of this type phase transformations, however, does not contain superfluous details and far better definition of the martensitic transformation no one could offer up to now. The formulation helps to understand the reasons for the huge run rate of MT: it is due to the collective, simultaneous movement of the atoms involved in the reconstruction of the original structure into martensite arising under cooling or under influence of the external actions. In this type of the phase transition, movement of the atoms over long distances does not require (they make up a share of the interatomic distances), while they themselves are carried out almost instantaneously.

It is well known that MT occurs not only in steels. The phase transition of this kind also occurs in the pure metals (Co, Fe, Ti, $\mathrm{Hf}$, Tl, etc.), many alloys based on copper, iron, cobalt, titanium, gold, and silver. It is observed also in polymer compounds.

A number of the experimentally established peculiarities of the martensitic transitions, such as high running rate at all temperatures and the inability to stop them (except isothermal MT) during external condition changes, independence of the martensite nuclea- 
tion and growth of the nuclei from the temperature, led to the conclusion about athermal nature of the MT.

However, in 1948 G. V. Kurdyumov, founding on his theory, concluded that at low temperature martensitic transformation could occur under isothermal conditions, at a constant temperature [2]. Experimentally isothermal MT was first discovered in FeNiMn alloys and later in other ferrous alloys [3-6]. In non-ferrous alloys, isothermal MT was first observed in the CuSn alloys alloyed with 12 wt.\% of $\mathrm{Ga}$ [6]. For example, in the CuSnGa alloys at a temperature $-196^{\circ} \mathrm{C}$, isothermal MT can continue for more than 40 minutes and depending on the alloy composition and state of the parent phase takes place in a wide temperature range: from $-196^{\circ} \mathrm{C}$ to $23^{\circ} \mathrm{C}$. The basic amount of the martensite arising by the isothermal kinetics appears during first 20-25 minutes. Using these alloys, it was shown that under change of cooling velocity or state of the parent phase by ageing or deformation in the same CuSnGa alloy it can observe different kinetics of MT in different sequences: isothermal, isothermal + athermal, athermal + isothermal [7].

The prediction of the thermoelastic transformation by G. V. Kurdyumov and subsequent experimental confirmation of this type of MT was very important for better understanding of the mechanism of MT [2, 8]. Open firstly in the CuAlNi alloys thermoelastic MT was later found in AuCd, AuAg, TiNi, CuZnAl, InTl and some other alloys. This transformation is characterized by low hysteresis (several tens of degrees), high mobility of the interphase boundaries (obligatory condition for thermoelastic MT, not only low hysteresis) when the external conditions (temperature, applied stress) change, the ability to stop the transition, full recovering of the initial state and orientation of high-temperature phase at heating (if avoid decay) or removal of the applied stress.

Usually for description of the martensitic transformation in a certain alloy, metastable diagrams are used. These diagrams show the temperature dependence of the beginning and end of the forward and reverse MT $\left(M_{s}, M_{f}, A_{s}, A_{f}\right)$ and hysteresis value on the composition, i.e. on the content of a specific (primary) element included in the alloy. Usually in the diagram, the temperature of equilibrium of the two phases (initial and martensitic ones), $T_{0}$, is noted too. The initial phase is stable above this temperature, and below it, the martensitic phase is stable.

Important parameters of the MT are the transformation temperatures, value of hysteresis and temperature ranges of the direct and reverse transition. Usually, hysteresis is taken as difference of temperatures at which $50 \%$ martensitic phase is formed during cooling and $50 \%$ of the parent phase when heating: $\left(M_{50}-A_{50}\right)$. Other methods are also offering for the hysteresis determination, for 
example, as temperature difference between the beginning of the $\operatorname{direct}\left(M_{s}\right)$ and start reverse $\left(A_{s}\right) \mathrm{MT}:\left(M_{s}-A_{s}\right)$.

\subsection{Morphology and Fine Structure of the Martensitic Crystals}

In the result of the macroscopic shear during MT, relief appears on the polished surface of the samples (Fig. 1) which disappears under heating during reverse transition to parent phase. By the methods of light and electron microscopy, a wide variety of the morphological shapes formed during cooling or under influence of the external loads is revealed in the martensitic phase.

There are several key forms: needle, tapered, strips, and plates of different thickness. All these forms are united by the common name: martensitic crystals. In one grain of the parent phase, up to 48 orientations of the martensitic crystals may arise.

The crystal growth occurs in both the longitudinal and transverse direction. Martensitic crystals in polycrystalline materials have dimensions from a few microns to a few millimetres (e.g., in $\mathrm{CuAlNi}$ alloys the martensitic crystals up to $7 \mathrm{~mm}$ observed). In the case of the thermoelastic MT, it can be seen a gradual increase of an individual crystal when the temperature or the applied stress changes.

During non-thermoelastic MT, crystals instantly grow to their final size and further MT takes place only through the formation of new martensite crystals. It should also be noted that the parent phase of the alloys in which thermoelastic MT proceeds often ordered: superstructure is observed there. Arising during cooling, martensite is also ordered.

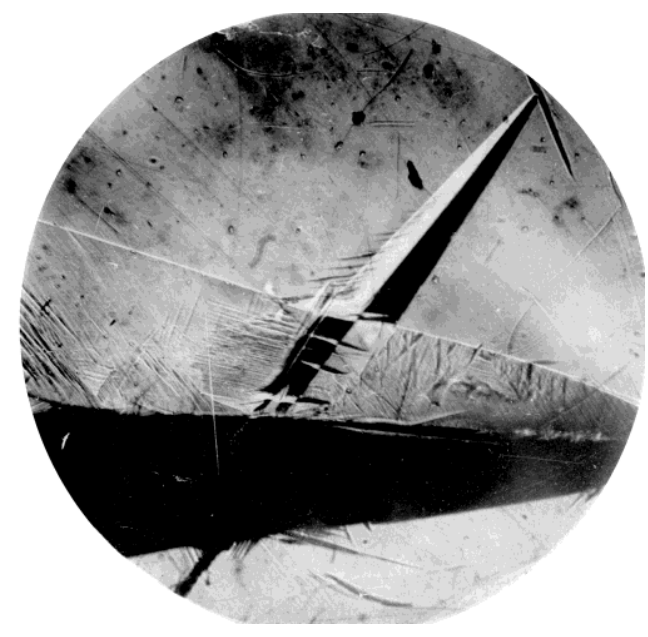

Fig. 1. Relief of the martensitic crystal in $\mathrm{Cu}-\mathrm{Al}-\mathrm{Ni}$ alloy $(\times 50)$ [9]. 
Decrease of the stress level encountered during MT proceeds often in the result of the formation of different groups consisting from the individual crystals-so-called self-accommodation systems of the martensitic crystals arise.

Morphology of the martensitic crystals depends on the concentration of elements in the alloy and external influences. For example, in CuAlNi (Mn) alloys at a concentration of greater than 14.2 wt. \% of $\mathrm{Al}$, wedge-shaped crystals ( $\gamma^{\prime}$-phase) appear, at a concentration of less than 13.8 wt.\% of $\mathrm{Al}$-plate (needle) crystals ( $\beta^{\prime}$-phase), and in the region 13.8-14.2 wt.\% of Al both morphological forms may occur $[9,10]$.

A great variety of the morphological forms appears during MT in other alloys. For example, in alloys $\mathrm{Fe}-(25-33)$ wt. $\% \mathrm{Ni}$, two main morphological forms may be observed: lath martensite $(\mathrm{Ni}$ concentration up to 29 wt.\%) and plate martensite (Ni concentration greater than 29 wt.\% of $\mathrm{Ni}$ ) or their different combinations, forming so-called farms, as well as needles, wedge-, lentils- and ribbonlike crystals [11]. In the $\mathrm{Ti}-(48-51)$ at.\% $\mathrm{Ni}$ alloys, two morphological forms of the martensitic crystals were found: the plate and socalled 'wavy' martensite [12]. The diamond-shaped crystals are observed also.

However, it should be noted that appearance of a particular morphological form of martensite is determined not only by the composition, the type of martensitic transformation and the type of arising phase (its crystalline structure), but depends also on external influences: quenching rate, temperature and subsequent cooling velocity, amount and type of application stress, the kind and extent of the irradiation, the grain size and thickness of the sample in which martensitic transformation takes place.

Arising during MT, crystals always contain one or more types of defects: thin twins, stacking faults, separate dislocations or dislocation forest. The appearance of the defect structure of the crystal is determined by the mechanism of the martensitic transformation. It is well known that formation of the martensite can be represented as two shifts: first, homogeneous, at which there is a simultaneous directed displacement of the atoms and, as a result, there arises macroscopic shear relief on the surface, and second, inhomogeneous necessary to obtain a final crystalline structure of the martensitic phase and leading to the appearance of the defect structure of the martensite [2, 13]. However, G. V. Kurdyumov emphasized that two shears proceed always concurrently but not in sequence one after the other [2].

Numerous studies of the defective martensitic structure by the electron microscopy showed that in alloys with thermoelastic MT (e.g., CuAlNi (Mn), CuZnAl, AuCd, TiNi) martensitic crystals usual- 


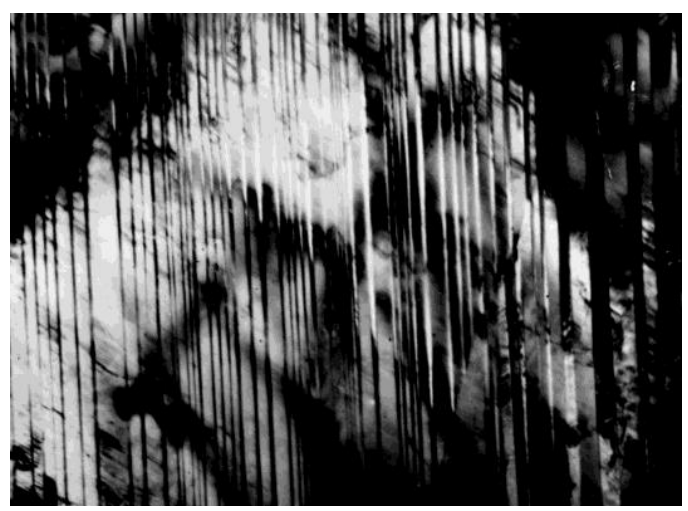

(a)

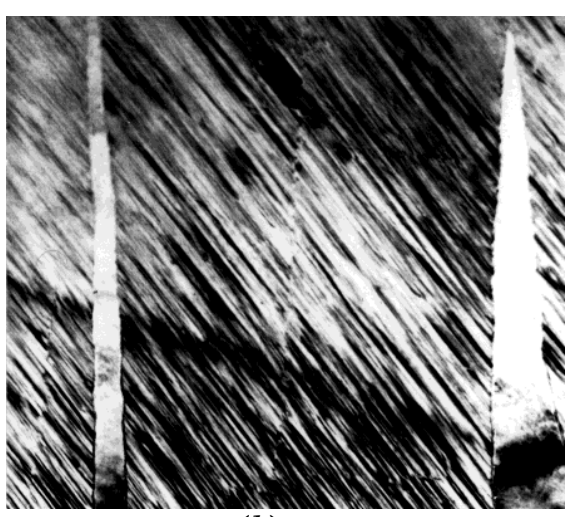

(b)

Fig. 2. The fine structure of the martensitic crystals in $\mathrm{Cu}-\mathrm{Al}-\mathrm{Ni}$ alloys $(\times 20000)$ [14]: $(a)$ thin twins, $(b)$ stacking faults.

ly contain a high density of thin twins (called 'transformation twins') and/or stacking faults [14, 15]. Figure 2 shows characteristic microstructures of the martensitic crystals in the $\mathrm{CuAlNi}$ alloys. In some alloys with thermoelastic MT (e.g., TiNi, CuZnAl), besides thin twins, the dislocations may be observed in crystals of martensite.

Defects arisen in the martensitic crystals during thermoelastic transformation are completely reversible and disappear during the reverse transition-formed parent phase does not inherit these defects. Many 'direct-reverse' MT cycles (more than 1000) can be accomplished but density of the defects in initial phase is practically unchanged and characteristic temperatures, transition intervals and hysteresis of the transformation are fully preserved.

A different situation arises during non-thermoelastic MT. For instance, in Fe-based alloys (the most prominent representatives of this MT type) formed during cooling, martensite contains a high density of the dislocations (the main types of defects), thin twins or stacking faults (for example, in CoNi alloys). Arising in nonthermoelastic martensite, defects are irreversible and during reverse MT are inherited by the parent phase increasing existed before transformation overall density of the defects, mainly dislocations (phenomenon of the so-called phase hardening).

During cycling in the range of MT in the result of accumulation of defects (mainly dislocations) in the parent phase, characteristic temperatures of transition are lowered, amount of martensitic phase appearing during following cooling decreases-the phenomenon of the stabilization of MT proceeds. Thus, influence of cycling in the intervals of the direct-reverse MT on the martensitic transition in 
these alloys is similar to the influence of the large (greater than $40-50 \%$ ) plastic deformations.

\subsection{Interphase Boundaries 'Martensite-Parent Phase': Structure, State, Mobility}

An important role in the proceeding of the direct-reverse MT plays interphase boundaries (IPB), their structure and state. Behaviour of IPB, their structure and state in the case of the thermoelastic and non-thermoelastic martensitic transformation are different. During non-thermoelastic MT, crystals instantaneously grow to its final value and, during changing the external conditions (temperature, applied stress), the sizes of the martensitic crystals do not change, that is, the boundaries of already arisen crystals preserve their position in the process of further transformation, which continues in this case by the formation of new crystals.

A different situation is observed in the case of thermoelastic MT. In this type of transformation, the martensitic transition can be stopped at any stage of cooling or change of the applied stress. Under lowering of temperature or increase of stress, existing crystals continue to grow, and new crystals may arise. When the temperature rises or after unloading, the martensitic crystals are gradually decreasing. Thus, the boundaries of the crystal retain its mobility during direct-reverse transition. However, some stress relaxation nevertheless occurs during this type of MT. This is evident due to the following observation. If cooling stops then, to continue the crystal growth, it is necessary some undercooling [8].

To explain high mobility of the interphase boundaries during thermoelastic MT, G. V. Kurdyumov introduced the concept of 'coherence' and 'coherent boundaries' [2]. Coherent boundaries arise during martensitic transition in the alloys based on $\mathrm{Cu}(\mathrm{CuAlNi}$ $(\mathrm{Mn}, \mathrm{Zn}))$, in $\mathrm{AuCd}$, TiNi (Cr, $\mathrm{Al}, \mathrm{Fe})$ and some other alloys, in which upon cooling or under applying of the external stress thermoelastic martensitic transformation occurs [14, 15]. During formation of the coherent boundaries, there should be observed complete conjugation of the corresponding crystal planes of the parent and martensitic phases and relaxation of the stresses arising during transformation should be absent.

The corresponding interplanar distances of the crystal structures of the parent and martensitic phases at the interface for full conjugation should be equal. However, in reality, it is impossible to find the corresponding planes in two phases with equal interplanar spacings on the interphase boundaries of the thermoelastic martensitic crystals, as they the most often located in the planes with low indexes and their interplanar distances in two phases are distin- 
guished. Therefore, there always will be some difference in the corresponding interplanar distances between these planes in two phases jointing on the IPB. This will inevitably lead and leads in reality to the appearance of the elastic deformations on (or near) the interphase boundaries of the thermoelastic martensitic crystals.

However, observations show that in this case the boundaries still retain high mobility. The relaxation of the arisen stresses (elastic deformations) leads in some cases to the appearance of the dislocations on the IPB, division of the boundary into separate coherent parts preserving own high mobility.

The structure and condition of the interphase boundaries in various alloys were examined in detail in a number of studies [14-19]. The authors of [17] proposed to divide the interphase boundaries into coherent, semi-coherent and incoherent. They are defined these boundaries in the following way.

Under full coherence at the IPB, there is observed perfect ('uniform' in the terminology of the authors [18]) match of the lattices of the parent and martensitic phase (actually a coincidence of certain planes of the crystal structures with the same interplanar distances).

In the case of the semi-coherent boundary, there is a certain relaxation (relaxation of the stress) and homogeneous of the matching decreases, although there may be some local matching in the local parts of IPB. It proceeds in the result of summing up of the uniform deformation, taking place during MT, and inhomogeneous deformation with invariant lattice (e.g., twinning or slip).

With formation of incoherent boundary, the continuity of the corresponding crystal planes in the parent and martensitic phases on the transition through IPB is disrupted completely.

Note that even in the case of thermoelastic martensitic transformation, IPB often has complex structure and sometimes there are observed dislocations. Even during thermoelastic MT, smooth boundaries are observed mostly during early stages of the transformation. As determined by the high-resolution electron microscopy, IPB, for example in the alloy $\mathrm{Ti}-\mathrm{Ni}$, consists of separate coherent portions, separated by interfacial dislocations [18].

But still found serrated and stepped IPBs of the martensitic crystals retain high mobility with changes of the temperature or applied stress. Such high mobility of the boundaries observed, for example, in $\mathrm{Cu}$ based alloys, TiNi, AuCd, etc. Misfit dislocations on the IPB frequently observed during MT in the FeNi alloys [19].

The boundaries between martensitic crystals, their structure, state and mobility play also great role in the deformation by means of the martensitic mechanism. Under influence of the external stresses, there can proceed next: growth of one martensitic variant at the expense of another, less favourably oriented with respect to 
the direction of the applied load, change of the orientation of twins inside given martensitic crystal and formation of the macroscopic twins or intermartensitic transitions. These processes occur at the temperatures below $M_{s}$.

Dislocation structure of the interphase boundaries 'parent phasemartensite' and the problem of their mobility were examined in several studies [17, 20,21]. The authors of these works have proposed to take into account two types of dislocations on the interface: coherent (dislocation of transformation) and anticoherent (called 'misfit' dislocations). Coherent dislocations are partial, they provide necessary of the deformation of the original lattice during its reconstruction into the lattice of the martensitic phase. The formation of the anticoherent dislocations (with lattice Burgers vector) brings to a violation of the correspondence (coherence) of the crystal structures on the boundary and proceeding of the deformation with an invariant lattice.

Coherent dislocations during their conservative movement lead to the appearance of the steps on the IPB but provide a conjugation of the crystal structures of the parent and martensitic phases on the boundary. Deformation energy arising during this movement is reduced in the result of formation of the anticoherent dislocations. Nevertheless, appearing of these dislocations reduces coherence on the IPB.

If invariant lattice deformation occurs as slip, the movement of the IPB is similar to the movement of the pile-up of the slipping dislocations [21].

Fulfilled investigations have shown that in the case of thermoelastic $\beta_{1} \rightarrow \gamma^{\prime}$ transformation in the CuAlNi alloys velocity of moving of the IPB in the temperature interval of $180-410 \mathrm{~K}$ is equal to $10^{-6}-10^{-2} \mathrm{~m} / \mathrm{s}$. The motion is thermally activated with an activation energy $(1.5-3.5) \cdot 10^{-20} \mathrm{~J}$, and activation volume is equal to $10^{3}-10^{4}$ atomic volumes [22].

In the topological model of MT, it is proposed to consider the phase boundary as consisting from the coherent sections separated by linear defects such as dislocations, steps and disconnections, which are formed together by steps and almost screw dislocations [23-25].

Defects of this type accommodate elastic deformations arising during transformation on the IPB. In fact, the interphase boundary

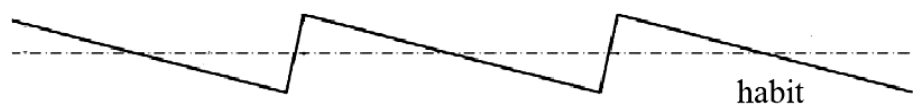

Fig. 3. The scheme of stepped interface boundary, where dashed line is interface boundary (habit) [24]. 


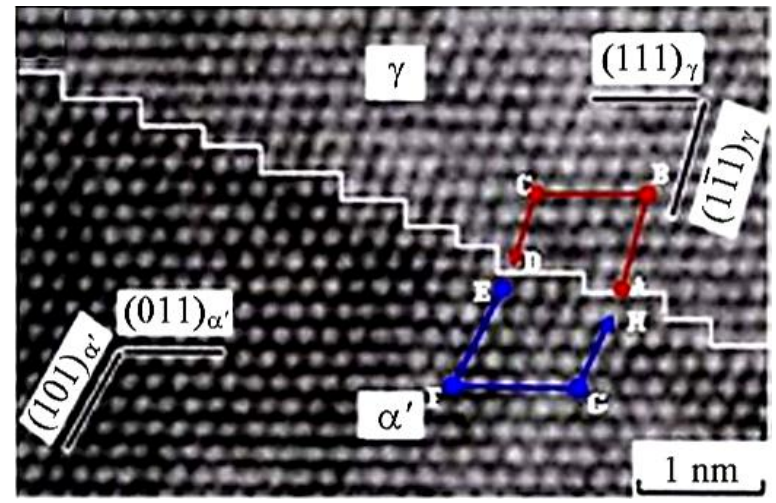

Fig. 4. Stepped interphase boundary in the $\mathrm{Ti}-\mathrm{Nb}$ alloys [26].

in this scheme is a certain line drawn through the steps and disconnections (Fig. 3). Crystallographic position of this boundary is determined by the height and extent of the steps. Own transformation occurs through lateral movement of the disconnections.

Thus, in contrast to the classical models of the phenomenological theories [15], in which IPB is regarded as invariant plane, in topological model the interface is semi-coherent configuration, consisting of defect-free coherent sections separated by the steps and disconnections [26]. Such stepped (on the atomic level) boundaries (Fig. 4) were detected by the studying of the structure of the interphase boundaries, using the methods of the high resolution electron microscopy in the alloys $\mathrm{Ti}-22 \% \mathrm{Nb}, \mathrm{Ti}-24 \% \mathrm{Nb}$ and $\mathrm{Fe}-20.2 \mathrm{Ni}-$ 5.4 wt. \% Mn [26].

\section{REVERSIBILITY OF THE MARTENSITIC TRANSFORMATIONS}

Reversibility of the martensitic transformations, a phenomenon discovered by G. V. Kurdyumov during investigations of the MT in eutectic copper-based alloys, consists in the reverse transition of the martensitic phase into parent one when the external influencestemperature (heating) or the applied stresses (their reduction)change. Reversibility during MT can be full or partial.

The degree of the reversibility is determined by the type of the martensitic transformation, reconstruction mechanism of the crystal structure of the parent phase into martensitic one (and martensitic phase into original one), kind of arising defect structure in the martensite, mobility of the defects and relaxation processes in these phases during direct-reverse transition and after their completion.

Reverse MT occurs the most complete (that is original state of the high-temperature phase restores) in the absence of the processes 
of stress relaxation and decomposition of the supersaturated solid solution, in which MT proceeds.

In addition to the defects, which have arisen during direct MT and inherited by the parent phase during reverse transformation, new structural defects such as dislocations, stacking faults, twins may additionally form as a result of the relaxation processes and interaction of the martensite crystals between themselves.

Completely reversible MTs were firstly found in the copper-based alloys $\mathrm{CuAl}(\mathrm{Ni}, \mathrm{Mn}, \mathrm{Co}), \mathrm{CuSn}, \mathrm{CuZn}(\mathrm{Al}, \mathrm{Ni}, \mathrm{Mn})$ and then in other alloys, in which thermoelastic MT proceeds: AuCd, AgCd, TiNi. It is necessary to note that if during reverse MT decay processes does not take place the original orientation of the parent phase and its state are completely restored.

Partially reversible MTs are observed in iron-based alloys $(\mathrm{FeNi}$, FeMn, FeNiCr), cobalt (CoNi), etc. In these alloys, nonthermoelastic MT occurs and during direct-reverse transition processes of stress relaxation take place which accompanied by the structural changes. It should be noted that in these alloys reverse MT is going at temperatures above $300^{\circ} \mathrm{C}$ at which relaxation processes occur more quickly.

Obtained experimental results, including microstructural observations, allowed to G. V. Kurdyumov draw an important conclusion that, during the reverse MT, movement of the atoms proceeds on the same paths as that of the forward, only in the reverse direction. This leads to the reversibility during this type of phase transitions.

\subsection{Mechanisms of the Reconstruction during MT}

The reversibility during MT is largely determined by the mechanism of reconstruction during this type of phase transitions: crystallography (orientation relationship of the parent and martensitic phases, plane and shear direction, orientation of the interphase boundaries), value of displacement of atoms included in transition, type of defects arising during reconstruction (dislocations, stacking faults, thin twins), their density, arrangement (crystallographic characteristics) and mobility.

Mechanisms and schemes of the reconstruction of the crystalline structures during MT in different metals and alloys detailed described in [15]. Therefore, we shall note that only the mechanism of the reconstruction during MT should provide for necessary crystalline structure of the new phase and its parameters, the correct relationship between parent and resulting phases, corresponding orientation of the interface (habitus) and type of the defects arising in the martensitic structure. And most importantly that shifts of atoms during this reconstruction should not exceed the interatomic 
distances and all the neighbours are saved, that is, the exchange of atoms does not occur.

Most of the proposed mechanisms and schemes consider the reconstruction of the parent structure into martensite through two shifts, which, as noted by G. V. Kurdyumov, do not occur one after other but certainly at the same time. The first shear (often called homogeneous since all atoms during reconstruction moved collectively in one direction) changes the crystal lattice of the parent phase and macroscopic shear proceeds leading to the appearance of the relief on the surface. The second shear (named heterogeneous) is required for receiving of the correct lattice parameters of the martensitic phase and formation of the martensitic microstructure with definite type of defects.

The first scheme of reconstruction of the parent lattice in the martensitic one was proposed by Bain in 1924 for MT in steel [27]. The assumption about two shifts during MT was used in the working out of the mechanisms of reconstruction in steels [28], zirconium [29], copper alloys [2] and other metals, as well as in the development of the phenomenological theories of the crystallography of the martensitic transformations [5].

\subsection{Defect Structure Changes During Direct-Reverse MT}

Numerous studies of the microstructure of the martensite formed during cooling or under influence of the external factors showed that along with its appearance from beginning stages of its growth the defect structure arises: dislocations, thin twins, stacking faults and various combinations of these defects.

Type of defects, their density in the crystals of the martensite, crystallographic characteristics are different in different alloys. They depend not only on the type of alloy but also on the proceeding type of MT and are determined by the mechanism of reconstruction and temperature (as, for example, in the $\mathrm{Fe}-\mathrm{Ni}$ alloys).

In alloys with thermoelastic MT, main type of defects, raised in the martensitic crystals, is thin twins (thickness of several nanometres) and stacking faults. Such defects are completely reversible and disappear together with martensite crystals during heating. This is due to their perfect crystallographic reversibility. For example, thin twins in the martensite of alloys $\mathrm{Cu}-\mathrm{Al}-\mathrm{Ni}$ were located in $\{121\}_{M}$ planes. During the reverse transformation, these planes turn into the $\{110\}_{A}$ planes, which are not the twinning planes in the parent (b.c.c.) phase. Therefore, twins (or other defects) during the reverse transformation in these alloys do not occur. Thus, the original state of the high-temperature phase that existed prior to the martensitic transition restored completely. It should be noted that in another 
alloys with thermoelastic nature of MT additional defects in the parent phase during the reverse transformation also are not formed.

During repeatedly cycling through the temperature intervals of the direct-reverse transition, new defects in the martensitic structure or in the high-temperature phase also do not arise. This is one of the important features of the MT with the thermoelastic nature of the transition. A perfection of the interphase boundaries (IPB) of the martensitic crystals and their high mobility are another feature of the thermoelastic MT. Movement of the boundaries during growth or decreasing of the martensitic crystal in this case can be stopped on any stage of the transformation and under further change of temperature or stress the same boundary starts to move again. Such boundaries often located in the planes with low index.

In the martensitic crystals (plates) of the alloys with nonthermoelastic MT, high density of dislocations (up to $10^{11} \mathrm{~cm}^{-2}$ ) and twins (e.g., in $\mathrm{Fe}-\mathrm{Ni}$ alloys) or stacking faults (in $\mathrm{Co}-\mathrm{Ni}, \mathrm{Fe}-\mathrm{Mn}$ alloys) are often observed. In the last case, martensitic crystals instantly grow to their final size, phase boundaries do not move with further changes of the external conditions (temperature or applied stress). During reverse transition, the arising parent phase inherits the defects of the martensitic phase and formation of new defects also proceeds. In the result, high density of defects (dislocations) appears and initial state of the parent phase is not restored. During repeated cycling through the temperature interval of MT, density of defects (dislocations) in the parent phase is greatly increased, the transformation temperature drops up to the full stop of MT that is stabilization of this phase takes place.

\subsection{Relaxation of Stresses Arising During MT}

Martensitic transformation is always accompanied by the appearance of the stresses both in the arising and parent phases. This is due to several reasons: the crystal lattices of the phases and theirs parameters are different, during the martensitic transition the volume changes occurs and at the interfaces of two phases a mismatch of the lattice spacings arises. Preservation of stresses (elastic energy) or their relaxation during MT (and after their finishing) leads to a number of peculiarities of this type of phase transitions.

During thermoelastic MT, the stress relaxation is practically absent or occurs in the result of the processes included in transformation, for example, by means of twinning in the martensite, formation of self-accommodation groups of the martensitic crystals, reorientation of already arisen martensitic crystals or transition of the martensitic phase appeared firstly into another one $\left(M_{1} \rightarrow M_{2}\right)$. All these processes are reversible and this causes the complete re- 
versibility (structural and crystallographic) of this type MT and recovery of the original state. Since the defects arisen during the direct MT are reversible (disappear completely on heating), the original structure is completely restored, temperatures of the forward and reverse MT and hysteresis are virtually unchanged.

Repeated cycling through the temperature intervals of the direct-reverse martensitic transition does not change the temperature parameters of MT. However, some relaxation of stresses arising during the MT can take place. This conclusion made on the basis of the microstructural investigations of MT in the alloys CuAlNi [8]. In this work, it was shown that after stopping of cooling further transformation proceeds only after some overcooling.

In the alloys with non-thermoelastic character of MT, as a result of stress relaxation, the dislocations appear, additional change of the defect structure of the parent phase proceeds, and it is possible the reorientation of already existing martensite crystals, for example, formation of macrotwins.

These processes are irreversible, and therefore, during reverse MT, the original state is not recovered or recovered only partially. In addition during reverse transition, the inheritance of the defects of the martensite phase and emergence of the additional defects occurs. Reverse MT also can occur not only by moving the interphase boundaries in the direction of the martensitic phase but also through the nucleation and growth of high-temperature phase in the martensite. All these processes lead to a change in temperature of the direct-reverse transition: their significant lowering and increase of hysteresis. Cycling through the transition interval may lead to stabilization of the parent phase and to complete suppression of MT in the case of the non-thermoelastic transition-that is a phenomenon called 'phase hardening' proceeds.

The significance of the stress and its relaxation on the proceeding and peculiarities of MT has been testified by experimental results obtained during investigation of MT in the $\mathrm{Cu}-(24-26)$ wt.\% Sn alloys [30, 31]. In these alloys during cooling, MT takes place with large hysteresis. However, at high heating rates (above 30 $\mathrm{K} / \mathrm{s}$ ) from $-196^{\circ} \mathrm{C}$, onset temperature of the reverse MT decreases (from $70^{\circ} \mathrm{C}$ to $0^{\circ} \mathrm{C}$ ), and hysteresis of transition is substantially lowered in comparison with those parameters which are observed during slow heating. Authors of [30,31] explained these changes by the influence of the preservation of the elastic energy stored during direct MT on rapid heating.

Preservation of the elastic energy is due to the suppression of the relaxation processes during high heating rates. Martensitic transformation, according to the authors, becomes thermoelastic, although movement of the phase boundaries in the direct and reverse 
transition was not observed in this study.

The effect of heating rate on the changes of temperature of the reverse MT was also observed in [32]. In this work fulfilled on the $\mathrm{Fe}-\mathrm{Ni}$ alloys, investigations showed that, at heating rate of 30 to $500 \mathrm{~K} / \mathrm{s}$, beginning of the reverse MT lowers from 360 to $270^{\circ} \mathrm{C}$, and end of the reverse MT changes from 420 to $360^{\circ} \mathrm{C}$. Additional lowering of these temperatures $(30-40 \mathrm{~K})$ occurs as a result of high-rate heating from the temperature of liquid nitrogen with rate $600 \mathrm{~K} / \mathrm{s}$.

At high-level stresses arising during direct MT, their relaxation during exposure in the martensitic state (below the temperature of the beginning of the reverse transition $A_{s}$ ) may lead to changes in the microstructure of the martensitic phase and fixing of the phase boundaries of crystals in the result of formation on these boundaries such defects as dislocations. Due to these processes, there is an additional increase in the temperature of the reverse MT and growth of hysteresis.

The authors of [33] proposed to consider two kinds of stress relaxation during MT-dynamic and static ones. Dynamic relaxation occurs in the process of martensitic transformation, and static one occurs after stopping or finishing of it. As a result of relaxation, the defect structure change occurs, and the states of the martensite and areas of the parent phase neighbouring to the martensitic crystals are changed too.

The second shear during MT which resulted in the change of the fine structure (arising of thin twins, stacking faults, dislocations and their various combinations) of the martensite may be presented as a result of dynamic relaxation needed to reduce the stress level during reconstruction of crystalline structure of the parent phase in new crystal structure-structure of martensite.

\section{UNUSUAL MECHANICAL PROPERTIES AND PHENOMENA CAUSED BY THE MARTENSITIC TRANSFORMATIONS}

The reversible martensitic transformations cause a number of unusual mechanical properties and phenomena. The main ones are as follow: shape-memory effect (SME), reversible (or two-way) SME (RSME), superelasticity (SE), superplasticity (SP). All these effects are caused by the MT, accompany it, and can be united under common name: shape memory effects.

These effects are more or less common to all reversible martensitic transitions and for different materials are distinguished one from another only by the value of the deformation accumulated during transformation and degree of the recovery of the initial size and state. However, superelasticity is possible only during thermoelastic MT.

Consider briefly the main peculiarities of these phenomena and 
properties, their distinctions in various types of MT in concrete alloys.

\subsection{Shape-Memory Effects}

Under applying of stresses (below yield limit) in the temperature interval of the direct MT, directional formation of the martensitic crystals takes place and accumulation of the reversible deformation proceeds. Such deformation may also occur in the result of reorientation of the unfavourably oriented martensitic crystals (variants), twinning (overtwinning) in the martensitic phase or intermartensitic transitions (transition one martensitic phase to another). Total amount of the deformation depends on the type of alloy and during thermoelastic MT can reach $10-25 \%$.

When load is removed and after heating above the temperature of the end of the reverse martensitic transformation $A_{f}$, the reverse reconstruction and recovery of the original size and state occur. This phenomenon is called 'shape-memory effect' (SME). Degree of the recovery depends on the type of MT. Figure 5 shows the dependence of the amount of accumulated during MT strain on temperature for various alloys [34]. Only in the case of thermoelastic MT (CuAlMn and TiNi), complete recovery is observed. During nonthermoelastic MT (FeNi), only partial recovery of the original shape occurs.

In alloys with athermal MT, accumulation of the reversible deformation occurs during continuous change in external conditionstemperature or applied stresses. However, in the case of isothermal martensitic transition, deformation caused by MT may occur at constant temperature without change of the applied stresses. For example, using alloys of $\mathrm{Cu}-\mathrm{Sn}-\mathrm{Ga}$, in which isothermal kinetics of MT occurs, it was shown that accumulation of fully reversible deformation may occur at constant temperature in the temperature range $\left[-196^{\circ} \mathrm{C} ; 20^{\circ} \mathrm{C}\right]$ and under constant applied stress during $20-$

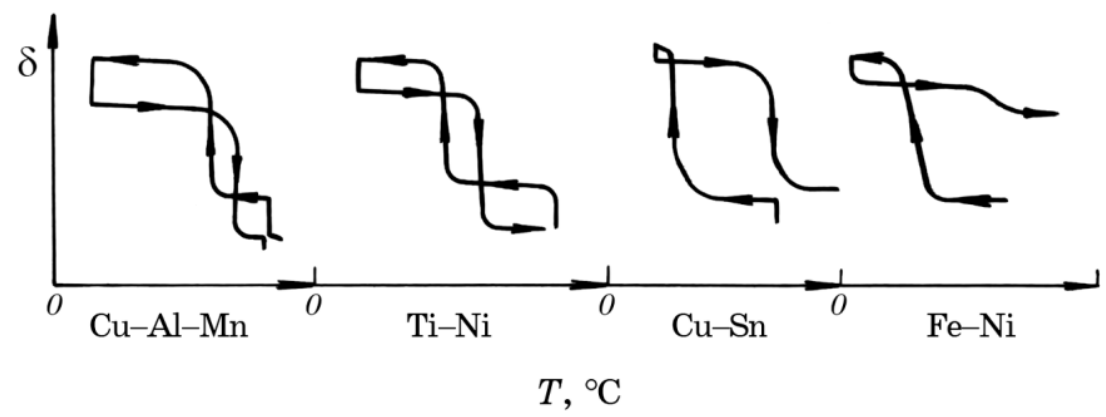

Fig. 5. Shape-memory effect in different alloys [34]. 
30 minutes [5, 6]. When removing the applied stresses and heating above $A_{f}$, there is complete recovery of the original state and size.

To evaluate the capabilities and range of application of the shapememory alloys, there are often used diagram 'stress-temperature' [35]. These diagrams show the dependence of the stress causing MT on the temperature, that is, in fact, the region of existence of the martensitic phase. Such diagrams can demonstrate the behaviour of the shape-memory alloys under different conditions: at various temperatures and magnitude of the applied stress.

The degree of return and recovery of the initial size and state is determined by the mechanism of the direct MT and type of defects arising in the martensitic phase. During thermoelastic MT, thin twins and stacking faults arise in the martensitic crystals, dislocations appear very rare (observed, for example, in the martensite of $\mathrm{Ti}-\mathrm{Ni}$ and $\mathrm{Cu}-\mathrm{Zn}-\mathrm{Al}$ alloys).

The crystal-structure characteristics of these defects (thin twins and stacking faults) are such that they provide their complete reversibility. As a result of the reverse MT, twins and stacking faults of the martensitic crystals disappear when removing the stresses and during heating. Complete $(100 \%)$ recovery was observed in the alloys based on copper, gold, silver, and in titanium-nickel alloy. In these alloys during MT, the initial b.c.c. structure is reconstructed into martensitic orthorhombic or rhombohedral structure, and, sometimes, in martensitic crystals, thin twins, stacking faults, lowdensity dislocations are formed.

During non-thermoelastic MT in the martensite, there is a high density of dislocations and thin twins. When heated above $A_{f}$, these dislocations do not disappear and are inherited by the hightemperature phase. Furthermore, during the non-thermoelastic MT, as a result of the reverse transition, additional dislocations are formed (essentially up to $10^{12} \mathrm{~cm}^{-2}$ ), the overall dislocation density increases. Thus, irreversible deformation proceeds in these materials. Inheritance of the dislocations of martensite arose during the direct transition and formation of the dislocations during the reverse transformation causes incomplete recovery of the initial state. Partial recovery occurs in the iron-based alloys, in cobalt. In these alloys, the parent f.c.c. phase during MT is reconstructed into b.c.c., b.c.t., or h.c.p. structure.

Significant influence on degree of the recovery in the alloys with non-thermoelastic MT has type of the substructure arising in the martensitic crystals. For example, it was observed that in the $\mathrm{Fe}-\mathrm{Ni}$ alloys with concentrations of 20-28 wt. $\%$ of $\mathrm{Ni}$ martensite with a high dislocation density arises upon cooling, with the content 28-32 wt. $\%$ of Ni dislocations, and thin twins are observed in the martensite and, at a concentration of more than $32 \mathrm{wt} \% \mathrm{Ni}$, martensite 


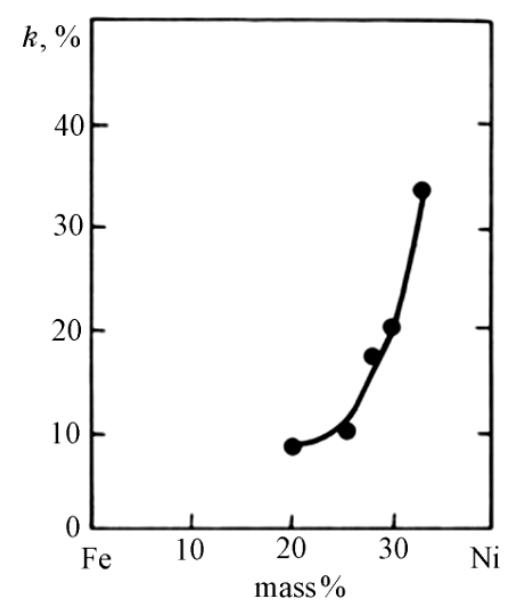

Fig. 6. The dependence of the recovery degree $(k)$ on the $\mathrm{Ni}$ concentration in the $\mathrm{Fe}-\mathrm{Ni}$ alloys [36].

contains mainly twins [5]. It was shown that degree of the recovery in these alloys during change of substructure of the martensitic crystals from dislocations to twins increases from $10 \%$ (for $\mathrm{Fe}-20$ wt. $\% \mathrm{Ni}$ ) to $35 \%$ (for $\mathrm{Fe}-32$ wt. $\% \mathrm{Ni}$ ) (see Fig. 6) [36].

In $\mathrm{Fe}-\mathrm{Mn}$ and $\mathrm{Fe}-\mathrm{Mn}-X(X=\mathrm{Si}, \mathrm{C}, \mathrm{Al}, \mathrm{Cr}, \mathrm{Ni})$ alloys in certain concentration range of manganese during cooling of the parent (f.c.c.) $\gamma$-phase, two martensitic phases $\varepsilon$ (h.c.p.) and $\alpha$ (f.c.c.) arise. However, SME due only to $\gamma \leftrightarrow \varepsilon$ transition and recovery of the original form in these alloys is always partial [37].

In Co-based alloys (alloyed with $\mathrm{Ni}, \mathrm{Al}$ and ternary complexly alloyed), martensite contains a high density of stacking faults which during reverse transformation transverse into dislocations. Accumulated during MT deformation in these alloys reaches up to $6.5 \%$ (in single crystals) and degree of recovery of the original shape can be varied from $30 \%$ after quenching (for alloys $\mathrm{Co}-\mathrm{Ni}$ ) up to $100 \%$ (in ternary alloys) for low loads (1\% strain) and after additional heat treatment [38-41].

The value of reversible strain accumulated during MT in single crystals of Co-based alloys during tension and compression is different. It has been shown that during tension of single crystals of the alloy $\mathrm{Co}_{40} \mathrm{Ni}_{33} \mathrm{Al}_{27}$ with orientation [001] reversible deformation is equal to $6.5 \%$ and on compression is only $3.7 \%$ [40]. In this alloy, the initial structure is $B 2+\gamma$ but upon cooling martensiticphase $L 1_{0}$ structure forms. The value of the reversible deformation depends also on the orientation of the single crystal. In single crystals of $\mathrm{Co}_{49} \mathrm{Ni}_{21} \mathrm{Ga}_{30}$ alloy (parent phase has the $L 2_{1}$ structure), it was shown that, during compression, reversible deformation for 
orientation [001] is $6.7 \%$, for the orientation [011] is $4.9 \%$, and for the orientation [123] is equal to $4.5 \%$ [40].

In some alloys, MT can proceeds at temperatures higher than $200^{\circ} \mathrm{C}$. At these temperatures, martensitic transformation is observed in $\mathrm{Zr}$-based alloys ( $\mathrm{ZrCo}, \mathrm{ZrCu}, \mathrm{ZrCuCo}, \mathrm{ZrCuNi}, \mathrm{ZrCoNi}$, $\mathrm{ZrRh}$ ), HfIr, TiTa [42-44]. For example, in alloy $\mathrm{Zr}_{2} \mathrm{CoNi}$, direct martensitic transformation is beginning at $600^{\circ} \mathrm{C}$ during cooling, and reverse transformation under heating is finished at $900^{\circ} \mathrm{C}$; martensitic transition is characterized by wide temperature hysteresis.

Unusual mechanical properties caused by MT-shape-memory effect, superelasticity, superplasticity-are also observed in Zr-based alloys. Recovery degree after removal of the load and heating to the temperature higher than temperature of the end of the reverse martensitic transformation reaches $90-100 \%$ [42].

In HfIr alloys of almost equiatomic composition (50.3 and 51.7 at. $\%$ Ir) after unloading and heating above $A_{f}$, complete recovery of the original shape is also observed [43]. Accumulation of deformation caused by MT (martensitic phase with an orthorhombic lattice arises) under external load of $270 \mathrm{MPa}$, and recovery of the initial state after removal of load takes place in the temperature range of $1000-500 \mathrm{~K}$. Value of the reversible deformation is substantially higher in the alloy with 50.3 at.\% Ir.

SME with complete recovery $(100 \%)$ of original size was also detected in the $\mathrm{Ti}-30 \mathrm{Nb}-3 \mathrm{Pd}(\mathrm{wt} . \%$ ) alloy in temperature range of 780-440 K [45]. Relatively high-temperature SME (in temperature range of $173-513 \mathrm{~K}$ ), stable during cycling, was manifested also in the alloys $\mathrm{Ti}-(30-40)$ at. $\%$ Ta [43]. To suppress the formation of $\omega$ phase that prevents the accumulation of the reversible deformation, the authors suggest to alloy the $\mathrm{Ti}-30$ at. $\%$ Ta with $\mathrm{Al}$ or $\mathrm{Sn}$ (1 at. $\%$ ) elements.

\subsection{Two-Way (Reversible) Shape-Memory Effect}

This type of reversible deformation caused by MT has various names: two-way shape-memory effect or reversible one. It is observed only under certain conditions, which permit the growth of the martensite crystals in one direction or close directions. This effect consists in following. As a result of generation of special microstructure in the parent phase, accumulation of the reversible deformation occurs by the directional growth of the martensitic crystals (only one variant or some close directions) during cooling without application of the external load and as a result of summation of the macroscopic shears of the growing crystals.

Such microstructure can be generated in several ways. For exam- 
ple, during ageing under stress, formation of segregations occurs along the direction determined by applying of an external stress and growth of the martensitic crystals proceeds in this direction. Another way consists in creating of the corresponding dislocation structure, such as slip lines, in parent phase. Such structure can be obtained by the deformation at temperature higher than the end of the reverse MT. Necessary microstructure may be also obtained by cycling in the temperature range of MT (cooling below $M_{f}$-heating above $A_{f}$ ) under the applied external stress.

With these microstructures, a growth of only one variant of martensitic crystals takes place and causes the summation of their shears and accumulation of the reversible deformation disappearing during heating above $A_{f}$. On repeating cooling below $M_{s}$, the same variant of the martensitic crystals arises as in the first cycle of the temperature change. Created microstructure of the parent phase is preserved during cycling through the interval of the direct-reverse MT long time as the temperature of the end of the reverse transformation $A_{f}$, for example, in Cu-based alloys, in alloys of TiNi and TiNi-Me ( $M e=\mathrm{Fe}, \mathrm{Al}, \mathrm{Co}$, $\mathrm{Hf}$ ), and in other alloys, is usually below $200-250^{\circ} \mathrm{C}$. At these temperatures, recrystallization processes during which pre-established dislocation structure can disappear yet do not take place. These temperatures are also significantly lower than the dissolution temperature of the precipitated particles.

It should be noted that multiple (repeated) accumulation of the reversible deformation with temperature change without applying of the external stresses (two-way shape memory effect) occurs only in the case of thermoelastic MT. This is due to the fact that only with this character of the martensitic transformation complete reversibility of MT and recovery of the state existing before transformation are observed.

Two-way shape memory effect is most often observed in CuZnAl alloys after deformation above $A_{f}$ or after cycling in the interval of MT during cooling under load and heating in unloaded state [46, 47].

\subsection{Superelasticity}

Superelasticity effect is caused by the formation of the martensitic phase during applying a stresses slightly higher than the temperature of the end of the reverse MT $A_{f}$ established for the transformation under cooling in unloaded condition. When removing the stress martensitic phase is unstable, a reverse transformation and return to its original condition and size take place. Superelasticity is observed only in the case of thermoelastic MT which proceeds with small (several tens of degrees) hysteresis. Superelasticity is observed at certain concentrations of the elements in $\mathrm{Cu}$-based al- 
loys (CuAlNi (Mn, Co), CuZn, CuZnAl), NiTi, NiTi-Me (Me = Fe, $\mathrm{Co}, \mathrm{Cr}, \mathrm{Al}), \mathrm{AuCd}, \mathrm{AgCd}$, and some others. Superelastic deformation caused by MT is $8-10 \%$ and in some cases may reach $15-18 \%$.

Superelasticity is also possible in the case of elastic twinning (overtwinning) in the martensitic phase under the influence of the external load or if there are several martensitic transitions when during application of the external stress one martensitic phase is formed from another martensitic phase: $A \leftrightarrow M_{1} \leftrightarrow M_{2}$. In the case of the superelasticity, due to intermartensitic transitions, effect is known as 'rubber-like behaviour'. The transition from one martensitic phase to another martensite under the influence of external stresses applied below $M_{f}$ is observed, for example, at certain concentrations of elements in ternary CuAlNi alloys [48].

Superelasticity (up to $4 \%$ ) also detected on single crystals of the CoNi alloys alloyed by $\mathrm{Ga}$ or $\mathrm{Al}[49,50]$. Superelastic deformation up to $3 \%$ also observed during f.c.c. $\leftrightarrow$ f.c.t. martensitic transformation in single crystals of $\mathrm{Fe}-30.8 \% \mathrm{Pd}$ alloy in temperature range of 255-355 $\mathrm{K}$ [51]. In this alloy during increase of temperature of the load (compression in the temperature range of 255$350^{\circ} \mathrm{C}$ ), decrease of the magnitude of the superelastic deformation proceeds and some hysteresis at temperatures of loading of 255 and $265^{\circ} \mathrm{C}$ is possible that is caused by the formation of the martensite under applying stress.

It should be noted that the value of superelasticity (SE) depends on the method of loading. Using the single crystals of $\mathrm{Co}_{49} \mathrm{Ni}_{21} \mathrm{Ga}_{30}$ alloy with orientation [001], it was shown that a plot of superelasticity obtained during tension and compression of single crystals have a different view (have asymmetry) [52]. The value of SE is also different. In both case of loading, SE is observed in temperature range up to $300^{\circ} \mathrm{C}$. Superelasticity during tension reaches $8.6 \%$, and there is a complete recovery of the original state when removing of the stress. In the case of compression, value of SE is only $4.3 \%$ and, at a temperature of $260^{\circ} \mathrm{C}$, irreversible $(1 \%)$ deformation appears. Authors explain its appearance by possible dislocation slip, difficulty of detwinning and some hardening caused by the work of friction. View of the graphs also depends on the temperature of applying of the stress (Fig. 7).

\subsection{Superplasticity}

The martensitic transformation is accompanied by some more effect (phenomenon)-superplasticity (another name is transformation plasticity, pseudoplasticity). Superplasticity (SP) is consist in the flowing of the material under external loading in the range of MT and caused by the martensitic transition at which, according to the 


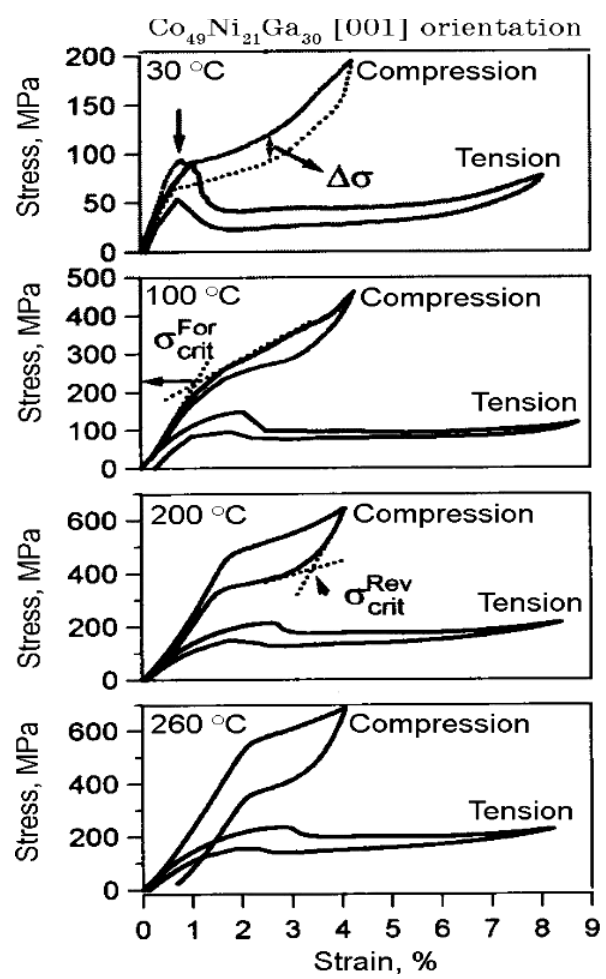

Fig. 7. Dependence of the superelasticity in $\mathrm{Co}-\mathrm{Ni}-\mathrm{Ga}$ alloys under compressive and tensile strains [52].

definition by G. V. Kurdyumov [2], atoms cooperatively displace in one direction on the distance not exceeding the interatomic. In fact, the value of SP is limited by these displacements. They are different in different alloys. The value of SP, for example, in CuAlNi alloys can reach 6-8\% [53]. Under the influence of the external stresses, directed formation of the martensitic crystals proceeds and, if stress removal occurs below the temperature of beginning of the reverse MT, deformation (elongation) is retained. The increased flow may also occur under external loading in the result of formation of the (macro)twins in already arisen (e.g., during cooling) martensitic phase or as result of the transition one martensitic phase into another martensitic phase as may occur in $\mathrm{CuAlNi}$ or TiNi alloys.

Superplasticity observed in all materials in which MT is possible during applying of the external stresses. However, in alloys with thermoelastic MT after stress removing and heating above $A_{f}$, the original dimensions and state are recovered. In the alloys with nonthermoelastic MT, deformed state is preserved completely or partly. 


\subsection{Memory Effects in Small-Size Objects}

For small-size materials, it should be included those objects whose size is limited in at least one direction: wire, films, obtained by different methods (thinning, spraying, high-speed quenching), powders. The size of these objects (diameter or thickness) is from 100 microns to $10-20 \mathrm{~nm}$. An important peculiarity of these objects is high probability of arising of the amorphous state during receiving (e.g., the films, prepared by rapid quenching from the liquid state) and the necessity for further heat treatment (annealing at elevated temperatures) for their transition into crystalline state.

Martensitic transformation in small objects occurs with certain peculiarity-characteristic temperatures (start and end of the forward and reverse MT), intervals of transition, hysteresis, phase composition (type of the martensitic phase, possibility of the intermartensitic transitions), reversibility, morphology and microstructure (type of thin structure) of the martensitic crystals, crystallography of the MT are varied [15, 54-56]. These changes are due to size factor-the influence of sizes of the object (thickness, grain size, etc.) on the characteristics of the martensitic transformations. They are largely caused by the changes in the processes of nucleation of new phase (for example, decreasing of number of the nuclei, change of their structure), increasing of role of the boundaries during MT, state of the surface, as well as with the processes of relaxation of stresses arising during MT.

As a rule, the value of the reversible deformation caused by the formation of the directed martensitic crystals under applying of the external stresses is less in small samples as compared with bulk materials. This is partly due to decrease of the number of identically oriented martensitic crystals in the objects of small dimension and to increase of number of the grain boundaries. In such objects, number of the nuclei of the martensitic phase decreases also, the smaller crystals are formed, and the fine structure of the crystals changes, differently in comparing to the massive objects relaxation processes and degree of its proceeding take place.

The composition, which can be changed during obtaining of small objects (for example, during deposition or heating for crystallization of amorphous films) has a significant influence on these properties. As a result, characteristic temperatures of the direct-reverse martensitic transformation, its intervals, hysteresis and, especially, the intervals of displaying of the unusual mechanical properties may change.

Degree of the recovery in small objects also depends on the type of MT and temperature intervals of transition. Only in the alloys with thermoelastic MT, recovery of the original shape is complete 
$(100 \%)$ and there is superelasticity without residual deformation.

\subsection{Influence of the External Impacts on Shape-Memory Effect and Recovery Degree}

The amount of strain accumulated during martensitic transformation under influence of external stresses depends firstly on the mechanism of reconstruction of the parent phase in new one. $\mathrm{Re}$ construction mechanism determines the value of the macroscopic shear and strain accumulated during transformation. However, an important role plays also the state of the parent phase and preliminary thermal and thermomechanical treatment, determining grain size of this high-temperature phase, existing and arising during transformation defect structure, value and temperature of the preliminary deformation.

Changing these parameters, it can greatly affect on value of deformation accumulated during MT and on degree of the recovery to the initial state after removing of the stresses and heating. When cycling in the range of the transformation under load, increase in number of the irreversible defects (dislocations, twins) can take place that in some cases will lead to change of the value of the strain accumulated during transformation. Once more reason may be decreasing of the amount of arising martensitic phase in the result of increasing of the defect density in the parent phase during cycling under load. Therefore, cycling in the temperature range of the 'direct-reverse MT' affects differently on degree of the recovery of the initial form and state.

In the case of the thermoelastic MT, cycling does not influence on these characteristics since defects of the martensitic phase (thin twins, stacking faults) are completely reversible, disappear during reverse martensitic transition and therefore are not accumulated on cycling.

Under non-thermoelastic MT arising during direct MT, defects (mainly dislocations) are irreversible. Therefore, after each cycle of the direct-reverse MT, density of defects in the parent phase increases. As a result, it changes the state of the parent phase, increases irreversible deformation that reduces degree of the recovery. However, in some alloys with non-thermoelastic MT, some increase in degree of the recovery may proceeds during cycling. For example, in $\mathrm{Co}-27$ wt.\% $\mathrm{Ni}$ alloys already after 3-4 cycles, recovery degree increases from 20 to $60 \%$ that can be explained by hardening of the parent phase in the result of increasing of density of dislocations arising during cycling [39].

In some materials, as a result of cycling, accumulation of defects and corresponding hardening of the material take place. In the study of cyclic loading (tensile deformation of $2 \%$ ) on the supere- 

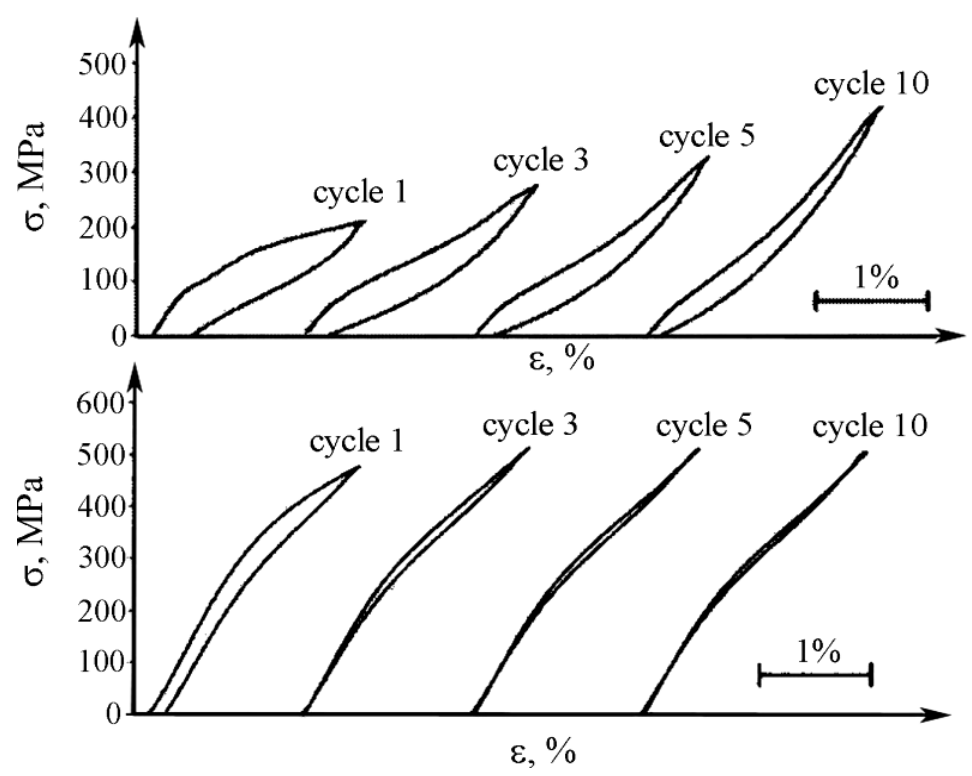

Fig. 8. Dependence of the superelasticity on cycling in the $\mathrm{Ti}-19.7 \% \mathrm{Nb}-$ $5.8 \% \mathrm{Ta}$ (above) and $\mathrm{Ti}-21.8 \% \mathrm{Nb}-6 \% \mathrm{Zr}$ (below) alloys [58].

lasticity, it was found that in nanostructured (subgrain size of about $100 \mathrm{~nm}$, small-angle disorientation) $\mathrm{Ti}-21.8 \mathrm{Nb}-6 \mathrm{Zr}$ and $\mathrm{Ti}-$ $19.7 \mathrm{Nb}-5.8 \mathrm{Ta}$ (at.\%) alloys after the first cycle some residual strain is preserved [58]. However, during subsequent cycles of 'loading-unloading', behaviour of these alloys is different: in Ti$21.8 \mathrm{Nb}-6 \mathrm{Zr}$ (at.\%) alloy full recovery is observed after 3 cycles, but in $\mathrm{Ti}-19.7 \mathrm{Nb}-5.8 \mathrm{Ta}$ (at.\%) alloy, some residual strain is retained after 10 cycle (Fig. 8). However, initial phase state of these two alloys is almost the same: at room temperature $\beta$-phase and limited amount of $\alpha^{\prime \prime}-, \omega$ - and $\alpha$-phases are present. Apparently, this difference during cycling can be explained by the fact that in these alloys during loading martensite with different properties and different thin structure arises. For instance, in the $\mathrm{Ti}-19.7 \mathrm{Nb}-5.8 \mathrm{Ta}$ (at.\%) alloy during the reverse transformation (after removal of the applied load), irreversible defects (e.g., dislocations or twins) appear.

Significant influence on the recovery degree exerts the composition of the alloy and additional alloying by some elements. Such influence was set in the alloys based on copper $(\mathrm{Cu}-\mathrm{Al}+(\mathrm{Ni}, \mathrm{Mn}, \mathrm{Zn}$, $\mathrm{Fe}, \mathrm{Co})$ ) and in several other alloys. A particularly significant increase in the degree of the shape recovery by alloying achieved in the alloys based on iron or cobalt. For example, when alloying of $\mathrm{Fe}-\mathrm{Mn}$ alloys with such elements as $\mathrm{Cr}, \mathrm{Si}$, recovery degree increas- 
es to $50 \%$ or more [59]. At a content of $26.8 \mathrm{wt} \%$ of $\mathrm{Mn}$ and 2.8 wt.\% of $\mathrm{Si}$ in $\mathrm{Fe}-(21-36$ wt.\% $) \mathrm{Mn}-(0.9-3.0$ wt.\%) $\mathrm{Si}$ alloys, the complete recovery of the original shape is observed.

The alloying elements are often selected as $\mathrm{Cr}, \mathrm{Al}$, rare earth metals, nitrogen, and carbon. Cycling under load in such $\mathrm{Fe}-\mathrm{Mn}$ alloys increases degree of the shape recovery to $100 \%$ [60]. However, it should be noted that magnitude of the reversible deformation in such alloys still does not exceed $2-3 \%$.

Growth of the recovery degree by alloying and cycling under stress is resulted in increase of the mechanical properties (hardening) and bring about to decrease in number of orientations of the martensitic crystals arising in the martensitic phase.

\section{CONCLUSIONS}

Experimental results obtained in the study of various aspects of the martensitic transformation indicate that this type of phase transitions can be represented as a special kind of deformationdeformation by the martensitic mechanism. Indeed, during MT, the change of sizes occurs as a result of the macroscopic shear, changes of the orientation and defect structure take place also. The martensite always contains twins, stacking faults, dislocations or various combinations of these defects. Upon cooling, martensitic crystals of different orientations arise (up to 24 orientations).

However, upon application of the external stresses, the crystals of preferred orientation arise and, in this case, the macroscopic shears of each crystal are added that leads to appearance of the total macroscopic deformation and in the result-to change of the size. When removing the stress and heating above the temperature of the end of the reverse transformation $A_{f}$, recovery of the original size, orientation and state proceeds.

Degree of the recovery depends on the nature of the martensitic transformation. In the case of thermoelastic MT, recovery is complete $(100 \%)$ due to the full reversibility of the defects arising in the martensite (thin twins and stacking faults) as dislocations during this type of the martensitic transformation is almost not formed.

During non-thermoelastic MT, irreversible defects such as dislocations and twins appear in the martensite. This defect structure is inherited by the parent phase during reverse transition. In addition, the dislocation density in the parent phase can be increased (up to $10^{11}-10^{12} \mathrm{~cm}^{-2}$ ) as a result of the formation of new defects during reverse transition. Their appearance is due to the mechanism of the reverse MT. All these processes cause return only part of the original form in the alloys with this type of MT. Thus, type of the defects arising during MT (so-called thin structure of the martensite 
crystals) and their reversibility (the ability to annihilate) largely determine degree of the recovery.

Second factor that affects reversibility is relaxation of the stresses arising during MT, rather, degree of relaxation. An important role of this parameter in the mechanism of MT noted repeatedly. It may be recalled about studies of MT conducted on the $\mathrm{Cu}-\mathrm{Sn}$ alloys [31], in which, as shown, in the case of retarding of the relaxation processes and preservation of the level of arising during direct MT stresses (due to the rapid cooling to the temperature of liquid nitrogen), the hysteresis of the transformation is considerably reduced and under heating fully reversible MT proceeds.

Increasing of the recovery degree in the $\mathrm{Fe}-\mathrm{Mn}$ alloys by alloying is due to the hardening and a corresponding decreasing in the degree of the relaxation processes. The role of dislocation deformation mechanisms lower also.

The recovery degree of the original shape (SME) depends strongly on the type of the thin structure of martensite. For example, in the $\mathrm{Fe}-\mathrm{Ni}$ alloys, it was shown that under change of the defect structure of martensite from dislocations to twins the recovery degree increases in three times (from $15 \%$ to $45 \%$ ) [35]. For complete recovery of the original shape (and state), it is needed that during the direct martensitic transformation such defects should arise which completely annihilate during reverse transition. Only thin twins and stacking faults, arising during direct thermoelastic MT, have these properties.

\section{REFERENCES}

1. G. V. Kurdyumov, Izvestiya AN SSSR. Ser. Khim., No. 2: 271 (1936)

(in Russian).

2. G. V. Kurdyumov, Zhurn. Tekhn. Fiz., 18, No. 8: 999 (1948) (in Russian).

3. G. V. Kurdyumov and O. P. Maksimova, Dokl. Akad. Nauk SSSR, 61, No. 1: 83 (1948) (in Russian).

4. O. P. Maksimova, Problemy Metallovedeniya i Fiziki Metallov [Problems of Physical Metallurgy and Physics of Metals] (Moscow: Metallurgizdat: 1952), p. 45 (in Russian).

5. V. A. Lobodyuk and E. I. Estrin, Uspekhi Fiz. Nauk, 175, No. 7: 745 (2005) (in Russian).

6. V. A. Lobodyuk and T. G. Sych, Fiz. Met. Metalloved., 60, No. 1: 90 (1985) (in Russian).

7. V. A. Lobodyuk and T. G. Sych, Metallofizika, 11, No. 1: 120 (1989) (in Russian).

8. G. V. Kurdyumov and L. G. Khandros, Dokl. Akad. Nauk SSSR, 66, No. 2: 211 (1949) (in Russian).

9. G. V. Kurdyumov, V. A. Lobodyuk, and L. G. Khandros, Kristallografiya, 6, No. 2: 210 (1961) (in Russian). 
10. K. Shimizu and K. Otsuka, Effekty Pamyati Formy $v$ Splavakh [Shape Memory Effects in Alloys] (Moscow: Nauka: 1979), p. 60 (Russian translation).

11. R. P. Reed, Acta Met., 15, No. 8: 1287 (1967).

12. S. R. Zijlstra, J. Beijer, and J. A. Klostermann, J. Mater. Sci., 9, No. 1: 145 (1974).

13. A. B. Greninger and A. R. Troino, Metals Trans., 185, No. 9: 590 (1949).

14. V. A. Lobodyuk, Thesis of Disser. for Dr. Techn. Sci. (Kiev: Institute for Metal Physics, A.S. Ukr.SSR: 1982) (in Russian).

15. V. A. Lobodyuk and E. I. Estrin, Martensitic Transformations (London: Cambridge International Science Publishing: 2015).

16. Yu. N. Koval and V. A. Lobodyuk, Deformation and Relaxation Phenomena During Transformation of the Martensitic Type (Kyiv: Naukova Dumka: 2010) (in Russian).

17. G. B. Olson and M. Cohen, Acta Met., 27, No. 12: 1907 (1979).

18. R. Sinclair and H. A. Mohamed, Acta Met., 26, No. 4: 623 (1978).

19. J. M. Penissson and G. Regheere, Mater. Sci. Eng. A, 107, No. 2: 199 (1978).

20. G. B. Olson, Acta Met., 29, No. 8: 1475 (1981).

21. M. Grujicic, G. B. Olson, and W. S. Owen, Met. Trans. A, 16, No. 10: 1713 (1985).

22. M. Grujicic, G. B. Olson, and W. S. Owen, Met. Trans. A, 16, No. 10: 1723 (1985).

23. J. P. Hirth, J. Phys. Chem. Solids, 55, No. 10: 985 (1994).

24. R. C. Pond, S. Celotto, and J. P. Hirth, Acta Mat., 51, No. 18: 5385 (2003).

25. R. C. Pond, X. Ma, and J. P. Hirth, Mater. Sci. Eng. A, 438: 109 (2006).

26. J. W. Howe, R. C. Pond, and J. P. Hirth, Progress in Materials Science, 54, No. 6: 792 (2009).

27. E. C. Bain, Trans. AIME, 70, No. 1: 25 (1924).

28. G. Kurdyumov and G. Sachs, Z. Phys., 64, No. 2: 325 (1930).

29. W. Burgers, Physica, 1, No. 6: 561 (1934).

30. P. V. Titov and L. G. Khandros, Ukr. Fiz. Zhurn., VIII, No. 1: 109 (1963) (in Ukrainian).

31. I. A. Arbuzova, Yu. N. Koval, V. V. Martynov, and L. G. Khandros, Metallofizika, No. 54: 34 (1974) (in Russian).

32. Yu. N. Koval, Uspehi Fiziki Metallov, 6, No. 2: 169 (2005) (in Russian).

33. Yu. M. Koval' and V. V. Nemoshkalenko, O Prirode Martensitnykh Prevrashchenij [On the Nature of Martensitic Transformations] (Kyiv: 1998) (Prepr./N.A.S. of Ukraine. Inst. for Metal Physics. No. 1, 1998) (in Russian).

34. V. A. Lobodyuk, Shape Memory Effect and Thin Structure of Martensite (Kiev: Izd. Znanie Ukr.SSR: 1980) (in Russian).

35. A. Fabregat-Sanjuan, F. Ferrando, Ch. Urbina, and S. De la Flor, Materials Science Forum, 738-739: 367 (2013).

36. V. I. Kolomytsev, V. A. Lobodyuk, and L. G. Khandros, Ukr. Fiz. Zhurn., 24, No. 3: 348 (1979) (in Russian).

37. A. Sato, E. Chishima, Y. Yamaji, and T. Mori, Acta Met., 32, No. 4: 539 (1984).

38. O. P. Grishchenko and V. A. Lobodyuk, Metallofiz. Noveishie Tekhnol., 22, No. 6: 66 (2000) (in Russian).

39. O. P. Grishchenko, V. A. Lobodyuk, Yu. N. Petrov, and L. N. Trofimova, Metallofiz. Noveishie Tekhnol., 24, No. 7: 897 (2002) (in Russian). 
40. Y. Chumlyakov, E. Panchenko, I. Kireeva, I. Karaman, H. Sehitoglu, H. J. Maier, A. Tverdokhlebova, and A. Ovsyannikov, Mater. Sci. Eng. A, 481: 95 (2008).

41. J. Liu, H. X. Zheng, M. X. Xia, Y. L. Huang, and J. G. Li, Scr. Mat., 52, No. 9: 935 (2005).

42. Yu. N. Koval, G. S. Firstov, J. V. Humbeeck, L. Delaey, and W. Y. Jang, Journ. de Physique IV. Suppl., 5: C8-1103 (1995).

43. Yu. N. Koval, G. S. Firstov, and V. Odnosum, Mater. Sci. Forum, 738-739: 72 (2013).

44. S. Miyazaki, H. Y. Kim, and P. J. S. Buenconsejo, 8th European Symposium on Martensitic Transformations-ESOMAT 2009 (Prague, Czech Republic), p. 2009-01003.

45. D. H. Ping, Y. Mitara, and F.X. Yin, Scr. Mater., 52, No. 12: 1287 (2005).

46. T. A. Schroeder and C. M. Wayman, Scr. Metall., 11, No. 3: 225 (1977).

47. C. Lee and S. Chung, Scr. Met., 23, No. 2: 161 (1989).

48. K. Otsuka, H. Sakamoto, and K. Shimizu, Acta Met., 27, No. 4: 585 (1979).

49. J. Dadda, H. I. Maier, I. Karaman, H. E. Karaca, and Y. I. Chumlyakov, Scr. Met., 55, No. 5: 55 (2006).

50. D. Meyer, I. Karaman, H. E. Karaca, and J. Dadda, Mater. Sci. Eng. A, 438-440: 875 (2006).

51. F. Xiao, K. Yashima, T. Fukuda, and T. Kakeshita, Mater. Sci. Forum, 738-739: 33 (2013).

52. T. Niendorf, J. Dadda, J. A. Monroe, I. Karaman, E. Panchenko, H. E. Karaca, and H. I. Maier, Mater. Sci. Forum, 738-739: 82 (2013).

53. K. Otsuka, C. M. Wayman, K. Nakai, H. Sakamoto, and K. Shimizu, Acta Met., 24, No. 2: 207 (1976).

54. V. A. Lobodyuk, Fiz. Met. Metalloved., 99: 29 (2005) (in Russian).

55. T. Waitz, W. Pranger, T. Antretter, F. D. Fisher, and H. P. Karnthaler, Mater. Sci. Eng. A, 481-482, No. 2: 479 (2008).

56. V. A. Lobodyuk, J. Phys. (France), 112: 735 (2003).

57. D. Gundarev, A. Lukyanov, E. Prokofief, A. Churakova, V. Pushin, S. Prokoshkin, V. Stolyarov, and R. Valiev, Mater. Sci. Forum, 738-739: 486 (2013).

58. S. Prokoshkin, V. Brailovski, M. Petrzhik, M. Filonov, and V. Sheremetyev, Mater. Sci. Forum, 738-739: 481 (2013).

59. A. Baruj, T. Kikuchi, S. Kajiwara, and N. Shinya, Journal de Physique IV, 112: 373 (2002).

60. M. Koyama, T. Sawaguchi, K. Ogawa, T. Kikuchi, and M. Murakami, Proc. of the Int. Conf. Martensitic Transformations 2008 (Warrendale, PA, USA: TMS: 2009), p. 583. 